\title{
Study of Psychological Distress among Sexual and Gender Minorities and Cishet Young Adults of India and United States of America
}

\author{
Vanshaj Gandhi ${ }^{1}$, Dr. Kamini C. Tanwar ${ }^{2}$
}

URL: https://doi.org/10.17762/pae.v58i1.831

DOI: $10.17762 /$ pae.v58i1.831

${ }^{1}$ Amity Institute of Behavioral and Allied Sciences, Amity University Haryana

${ }^{2}$ HoD-BS \& Associate Professor-AIBAS, Amity University Haryana

Contact Info: vanshajgandhi99@gmail.com, kaminic03@gmail.com

\section{Abstract}

The decriminalization of homosexuality on September 6, 2018 in India has led to focus of Indian researchers towards mental health of Sexual and Gender Minorities (SGMs) who face day-to-day challenges such as social-unacceptance, identity suppression, discrimination and hate crimes. The present study focuses on analyzing psychological distress among one of the most developed country i.e., United States of America (US) and the fast-developing country i.e., India with the inclusion of the LGBTQ+ and Cishet population. To fulfil the objective, data was collected from 200 young adults falling under 18-40 years of age from both Indians $(\mathrm{N}=100)$ and Americans $(\mathrm{N}=100)$ through Purposive Sampling Technique. Furthermore, there were 50 LGBTQ + and 50 Cishet sample in both group of each country. The responses were collected through Survey Monkey. Every respondent was individually assessed using Kessler's Psychological Distress Scale (K10; Kessler et al., 2002) for evaluating the extent of psychological distress in the individual. The data analysis was done by Independent sample t-test using IBM SPSS software. The results indicate that 1.) Young adults of India have higher psychological distress than that of Americans as well as both the group (LGBTQ+ and Cishet Population) of India have higher psychological distress than that of the US; 2) LGBTQ+ population has higher psychological distress in comparison to Cishet population in both India and US as well as for young adults.

Keywords: Sexual and Gender Minorities, LGBTQ+, Cishet, Psychological distress

Article Received: 10 August 2020, Revised: 25 October 2020, Accepted: 18 November 2020

\section{Introduction}

Intersectionality is a gift of diversity giving us a sense of community and connectedness. The categorization of individuals under various classifications has been aimed at understanding characteristics of specialized groups. But through socio-political prejudices and changing intrahuman dynamics, intersectionality has been viewed as means to segregate communities through toxic labels. One of the communities that has seen adverse effects due to consequential discrimination is the LGBTQ+ community (acronym representing Lesbian, Gay, Bisexual, Transgender, Queer and More). This community includes individuals who unlike most of the population don't identify themselves as Cishet (heterosexual and cisgender) therefore also referred to as Sexual and Gender Minorities (SGM). The LGBTQ+ community or
SGMs includes people with different sexual orientations such as- homosexuality, bisexuality, polysexuality, pansexuality, asexuality etc. and/or gender identities such as- transgender, agender, nonbinary, gender-fluid, gender non-conforming etc. Even intersex individuals are included in SGMs.

Unlike the common assumption biological sex, gender and sexual orientation are three different identities which are mutually exclusive. Sexual orientation and gender identity are both fundamental identity components that are present in every individual. Sexual orientation consists of an individual's sexual and emotional attraction towards another individual or self and the behavior resulting from this attraction. An individual may be attracted to either men, women, both, neither, and/or to individuals having other gender identities. Gender identity is a complex identity that is an individual's 
deeply felt sense of self, perceiving themselves as either masculine, feminine, both or neither according to the gender norms. Gender identity is internal and may not be necessarily visible to others since it can only be felt. Gender identity doesn't always have congruence with an individual's biological sex that is assigned at birth or to a person's primary and/or secondary sex characteristics e.g., after birth the baby is assigned to be male (biological sex) by observing genitalia but while growing up may feel more feminine and hence might identify with different gender identity (American Psychological Association, 2015).

Young adulthood is seen as a fundamental period of growth and highly critical period of development since we start expressing most of our psychosocial attributes like identity, social cognition, personality $\&$ morals. Around this time, one also starts sexual experimentations leading to knowledge, expression and nurturance of our sexual orientation \& gender identity. Psychosocial researches on the youth would help us understand and map down the trends in behavior during the dynamic life environment and conditions like education, employment, home security, relationship quality, community involvement etc. (Davis et al., 2011; National Academic Press, 2015)

Around the globe people are attacked for who they love, how they dress and who they are. SGMs are still believed to be mentally ill and/or culture betraying sinners since they are considered to be sociocultural and ideological deviation. The consequential backlash leads to one's identity suppression that is defended in the name of morality, religion and public health (Amnesty International, 2001). Out of 195 countries, around 70 countries still criminalize same-sex activity and out of which around 12 countries have death penalty for the same (Wareham, 2020). Even in the countries where same-sex activity is legal, LGBTQ+ individuals still may face discrimination in forms of range of unequal treatment, purposeful misgendering, name-calling, bullying, verbal and physical abuse, harassment, hate crime or even murder due to heteronormative cultural upbringing that promotes heterosexism accounting for internalized queer-phobia. The uncertainty and fear of unacceptance of their identity and discrimination can cause psychological distress and mental health issues.
Psychological Distress (PD) is a state of emotional suffering that causes psychological discomfort affecting one's mood and level of functioning negatively causing emotional turmoil. PD is caused due to the exposure with external events and/or stressors placing physiological and psychological demands upon us that we are unable to cope with effectively and hence causes psychological discomfort, since it is a maladaptive response to a stressor. It is a subjective experience because the severity of PD depends on the stressor, situation and how we perceive it. It can be manifested in forms of anxiety, sadness and symptoms of mental illness. Excessive PD can indicate mental health issues therefore PD can be used as an indicator of mental health of the population. (Mirowsky and Ross, 2003; Drapeau et al., 2012; Ridner, 2004; Horwitz, 2007).

Insecurities and fear of facing negative evaluations from others have been one of the unwanted resistances in the journey of self-acceptance for every marginalized community including SGMs. Comingout is a process where the person decides to disclose their sexual or gender identity to their family, friends and/or acquaintances specifically as a part of the LGBTQ+ community. It is one of the most stressful processes for SGMs due to the uncertainty of reaction from the person next to them. Family estrangement of SGM youth has been quite high hence before comingout one might question the social support, resources and financial stability. A study in the US showed that around $40 \%$ of SGMs are disowned and thrown out by family after coming out (Durso \& Gates, 2012). On the other hand, more than $90 \%$ transgender people are disowned in India (Chauhan, 2018). Research suggests that societal unacceptance of one's sexual and gender identities impacts both safety and mental health of SGM and this discrimination is believed to be linked with high rates of mental health issues \& psychiatric disorders. Even suicidal ideation in SGMs is twice more likely than cishet counterparts (Mental Health America, nd)

Humans regardless of their gender identity and sexual orientation may experience a variety of stressors due to unpredictable life circumstances and transitions which include environmental, financial, social, academic, intrapersonal, interpersonal, cultural, physical, psychological, spiritual, developmental and work-related changes that need appropriate biopsychosocial adaptations. When these adaptations are not effective against stressors then it may cause distress in the individuals. An individual identifying 
both as cisgender and heterosexual are referred to as cishets and it is the society's predominant presumption of an individual's identity. Due to the lack of psychoeducation on the topic of gender and sexuality some believe that all heterosexuals identify as cisgenders which is far from the truth. Getting pressed between toxic masculinity and femininity due to forced gender norms are not only a burden to SGMs but many cishets too. Some cultures have more strict gender roles that could create a sense of alienation and hence distress.

India and United States of America do not have much in common and there is an expected difference in PD between the two nations due to the variations in their dominant cultural styles, family systems, economic status, socio-political environment, education systems \& developmental status; US being a developed nation and India being a developing one etc., a quantitative analysis would provide us concrete result. This result will give us a substantial information regarding mental health across both the countries since research gap has been found during literature review for the same.

\section{Objectives}

1. To compare psychological distress among Indians and Americans in Young Adults, LGBTQ+ population and Cishet population.

2. To compare psychological distress between LGBTQ+ and Cishet population of Young Adults, India and US

\section{Hypothesis $\left(\mathrm{H}_{1}\right)$}

1. Psychological Distress will be higher among Indian than Americans in: -
1.1. Young Adults
1.2. LGBTQ+
1.3. Cishet

2. Psychological Distress among LGBTQ population will be higher than the Cishet population in: -

2.1. Young Adults

2.2. India

2.3. US

\section{Methods}

\section{Participants}

Data was collected from 200 students and working individuals of age range 18 to 40 by the method of purposive sampling technique. The data includes 100 American \& 100 Indian sample. Per country there was an inclusion of 50 sexual and gender minorities i.e., lesbian, gay, bisexual, transgender, pansexual, polysexual, genderfluid/genderqueer individuals and 50 Cishet individuals that means in total there were 100 LGBTQ+ and 100 Cishet respondents. The sample did not include data from non-working individuals or any politician, celebrity and/or public figures. None of the sample was collected from individuals having medical conditions or who are in hospitals or in critical care to eliminate biasness due to medical conditions. Most importantly the sample did not include any parasexual individuals since they are not a part of the LGBTQ+ community. No sample was taken from individuals who are still unsure about their sexual orientation and/or gender identity. Lastly, no sample from Alaska (US) and Jammu and Kashmir, Daman and Diu and Andaman and Nicobar Islands (India) was collected.

\section{Table 1}

Bifurcation of the sample size

\begin{tabular}{lcc}
\hline Sample Bifurcation & India & US \\
\hline LGBTQ+ population & 50 & 50 \\
Cishet population & 50 & 50 \\
Sample size per-country & 100 & 100 \\
Total sample size & \multicolumn{2}{c}{200} \\
\hline
\end{tabular}

\section{Materials}

Kessler's Psychological Distress Scale (K10; Kessler et al., 2002) was used in the present research. It's a 10-item brief self-report measure that aims to assess non-specific psychological distress in the respondents. This scale is unidimensional and measures PD in the respondent over 4-week period. The K10 Scale has a 5-point Likert response categories that includes- "All the time", "Most of the time", "Some of the time", "A little of the time" and "None of the time" that are scored 5 to 1 respectively and hence making the scoring range 10 to 50 . A higher score on K10 indicates higher psychological distress in the individual. For the aboriginal populations K10 scale has acceptable internal consistency with Cronbach's alpha $\alpha=0.88$ and it also showed significantly positive inter-item correlations ranging from 0.30 to 0.70 (Bougie et al., 2016). K10 has also been validated for developing countries including India (Patel et al., 2008). 


\section{Design and Procedure}

The present research is quantitative in nature and the research design is comparative. For obtaining the results, Independent sample t-test has been used and for data analysis IBM SPSS version 25 was used. The responses were taken through purposive sampling and data was collected through SurveyMonkey (an online survey development software). Participants were reached out through social media websites- Instagram \& Twitter and were given the link of the questionnaire. The respondents were provided the following instructions accompanied with the link to the questionnaire after establishing online rapport- "This is a research being conducted by XYZ. Your Identity and Information obtained through you for this study will be kept strictly confidential. This is a psychological assessment that aims to analyze distress in the individuals. Please be honest and choose the most suitable option."

\section{Ethics}

The research meets all applicable standards regarding to the ethics of experimentation and research integrity including taking consent \& confidentiality.

\section{Results}

\section{Table 2}

Showing difference on Psychological Distress between India and US in (1) Young Adults, (2) LGBTQ+ and (3) Cishet Population

\begin{tabular}{|c|c|c|c|c|c|c|c|}
\hline \multirow[t]{2}{*}{$\mathrm{H}_{1}$ no. } & \multirow[t]{2}{*}{ Population } & \multicolumn{2}{|c|}{ India } & \multicolumn{2}{|c|}{ US } & \multirow[t]{2}{*}{$\mathrm{t}$} & \multirow[t]{2}{*}{$\mathrm{p}$} \\
\hline & & Mean & SD & Mean & SD & & \\
\hline 1.1 & Young Adults & 26.6600 & 7.82797 & 22.2100 & 7.06291 & 4.221 & $0.00003^{*}$ \\
\hline 1.2 & $\begin{array}{l}\text { LGBTQ+ } \\
\text { Population }\end{array}$ & 28.5800 & 8.02061 & 24.2800 & 7.27321 & 2.808 & $.006^{*}$ \\
\hline 1.3 & $\begin{array}{l}\text { Cishet } \\
\text { Population }\end{array}$ & 24.7400 & 7.20773 & 20.1400 & 6.25646 & 3.408 & $.001 *$ \\
\hline
\end{tabular}

$* \mathrm{p}<.01(99 \%$ confidence level $)$

35

30

25

20

15

10

5

0

1.1 Young Adults

Figure 1: Showing difference in the mean of Psychological Distress among India and US.

Analyzing data from Table 2 (for Hypothesis 1): -

1.1. For Young Adults, the mean value of PD in Indians is 26.66 with standard deviation of 7.83 and the mean value of PD in Americans is 22.21 with standard deviation of 7.06. The corresponding $\mathrm{t}=4.22$ with $\mathrm{P}$ value 0.00003 , (99\% confidence level) suggesting a statistically significant difference in PD between young adults of India and US. Therefore, it can be concluded that there is a significant difference suggesting that young adults in India have higher Psychological Distress than that of US.

1.2. For LGBTQ+ Population, it is clearly visible that the mean value of PD in Indians is 28.58 $(\mathrm{SD}=8.02)$ and in Americans is 24.28 with $(\mathrm{SD}=7.27)$. The corresponding $\mathrm{t}=2.81$ with $\mathrm{P}$ value .006 , representing a significant difference in PD between LGBTQ+ population of India and US. Hence, LGBTQ+ individuals in India have statistically higher and significant Psychological Distress than that of US.

1.3. In Cishet Population also, the mean value of PD in Indians is 24.74 with standard deviation of 7.21 and in Americans is 20.14 with standard deviation of 6.25 having $\mathrm{t}=3.41$ significant at .01 level. Hence, it can be concluded that there is a significant difference suggesting that Cishet individuals in India have statistically higher Psychological Distress than that of US. 


\section{Table 3}

Showing difference on Psychological Distress between LGBTQ and Cishet population in (1) Young Adults, (2) India and (3) US

\begin{tabular}{clcccccc}
\hline \multirow{2}{*}{$\mathrm{H}_{1}$ no. } & Population & \multicolumn{2}{c}{ LGBTQ $^{+}$} & \multicolumn{2}{c}{ Cishet } & $\mathrm{t}$ & $\mathrm{p}$ \\
\cline { 3 - 6 } & & Mean & SD & Mean & SD & & \\
\hline 2.1 & Young Adults & 26.4300 & 7.91783 & 22.4400 & 7.10146 & 3.751 & $0.0002^{*}$ \\
\hline 2.2 & India & 28.5800 & 8.02061 & 24.7400 & 7.20773 & 2.518 & $.01^{*}$ \\
\hline 2.3 & US & 24.2800 & 7.27321 & 20.1400 & 6.25646 & 3.051 & $.003^{*}$ \\
\hline
\end{tabular}

$* \mathrm{p}<.01(99 \%$ confidence level $)$

35

30

25

20

15

10

5

0

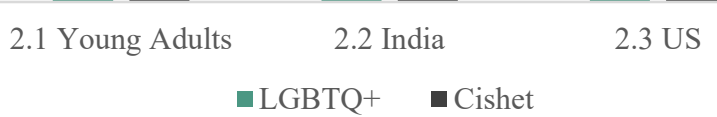

Figure 2: Showing difference in the mean of Psychological Distress among LGBTQ+ and Cishet population.

Analyzing data from Table 3 (for Hypothesis 2): -

2.1 For Young Adults, the mean value of PD in LGBTQ+ individuals is 26.43 with $7.92 \mathrm{SD}$ and in Cishet individuals is 22.44 with standard deviation of 7.10. The corresponding $\mathrm{t}=3.75$ and at .01 level a statistically significant difference is found in PD between young adults of LGBTQ+ and Cishet population. Therefore, it can be concluded that there is a significant difference suggesting that LGBTQ+ young adults have statistically higher Psychological Distress than that of Cishet Young Adults.

2.2 In Indian Population, it is clear that the mean value of $\mathrm{PD}$ in $\mathrm{LGBTQ}+$ individuals is 28.58 (8.02 SD) and in Cishet individuals is 24.74 (7.21 SD) with $t=2.52$ significant at .01 level, suggesting a statistically significant difference in PD between LGBTQ+ and Cishet population in India. Hence, LGBTQ+ individuals in India have statistically higher and significant Psychological Distress than that of Cishet individuals.
2.3 In US Population, the mean value of PD in LGBTQ+ individuals is $24.28(\mathrm{SD}=7.27)$ while in Cishet individuals is $20.14(\mathrm{SD}=6.26)$ having $\mathrm{t}=3.05$ significant at .01 level depicting a significant difference in PD between LGBTQ+ and Cishet population in US. Hence, it can be concluded that LGBTQ+ individuals in US have statistically higher \& significant Psychological Distress than that of Cishet individuals.

\section{Discussion}

The present cross-country research compared psychological distress in India and US with the inclusion of Sexual and Gender Minorities. Researches regarding the mental health of LGBTQ+ individuals across the globe would help make a positive impact that will contribute to academic psychoeducation on community cohesiveness \& intersectionality. Even after the decriminalization of homosexuality in India there are no specific laws that protect LGBTQ+ individuals as well as there are no anti-discrimination laws, laws against conversion therapy, laws for same-sex marriage etc. The number of hate crimes that have been documented against SGMs is disheartening. Verbal abuse \& using derogatory terms might escalate to physical intimidation creating a mentally torturous environment for SGMs. Our differences in sexual, romantic and gender preferences shall not discount our love. We all are worthy of love, dignity, respect $\&$ equality that has been shown by allies with their acceptance all around the world.

The data analysis using independent sample t-test suggested that Indian young adults have higher psychological distress than that of Americans and similarly both the groups (LGBTQ+ and Cishet Population) in India have higher psychological 
distress than that of US (Table-2). It can also be seen that LGBTQ+ young adults have higher psychological distress than that of Cishet population, this is also consistent in both the countries (India and US) individually (Table-3). It can be noticed that all the hypotheses (namely H1.1, H1.2, H1.3, H2.1, $\mathrm{H} 2.2 \& \mathrm{H} 2.3$ ) are accepted. After looking at both the tables we can also see that with a mean of 28.58 , Indian Sexual and Gender Minorities have the highest psychological distress than any other group. Similarly, from both the tables it can also be seen that with a mean of 20.14, Cishet Americans have the least psychological distress than any other group.

Generation- $Z$ and millennials have been well focused on understanding the importance of mental health and its awareness. Every nation shall take mental health seriously and its awareness an essential element in their growth and development by embedding mental health rights in their system. Psychological Distress is seen as one of the indicators of mental health (Drapeau, 2012) and it can be experienced by any individual at any point of time due to the psychosocial environment. Cultural predisposition in a community might impact the intensity of stressors, hence there is a relevance in understanding the sociopsychological variables and their differences between countries. We can see by the results that overall Americans have less psychological distress than Indians which is supported by the research on Happiness Index (HI) by United Nations that analyzed Happiness Index of 153 countries and found that United States ranks at 18 while India ranks at 144 in the same report (Helliwell et al., 2020).

It makes a prominent impact if we shine a light on inclusivity of different minority groups be it racial, ethnic, gender etc. and making mental health discrimination against minority groups objectionable and intolerable. Gender norms can be quite limiting in nature and sometimes people see themselves trapped inside a prison cage of forced gender norms by societal pressures. What sometimes people miss is that the rebellious clothing or makeup that opposes to the contemporary view of gender norms is not just any cream or powder nor just a dress, it's part of how they feel and how they would like to be seen. We shall embrace the power we hold within to fully nurture ourselves \& celebrate both of our femininity and masculinity regardless of our biological sex. At last, we'll be who we're meant to be once we start seeing ourselves through the mirror within.

\section{CITATION}

Gandhi, V., \& Tanwar, K. C. (2021). Study of Psychological Distress among Sexual \& Gender Minorities and Cishet Young Adults of India and United States of America. Psychology And Education, 58(1), 789-798.

https://doi.org/10.17762/pae.v58i1.831

\section{References}

American Psychological Association. (2015). Guidelines for Psychological Practice with Transgender and Gender Nonconforming People. American Psychologist, 70(9), 832864. https://doi.org/10.1037/a0039906

Amnesty International. (2001). Crimes of Hate, Conspiracy of silence: Torture and Illtreatment Based on Sexual Identity. London, UK. Amnesty International Publications.

Bougie, E., Arim, R. G., Kohen, D. E., and Findlay, L. C. (2016). Validation of the 10-item Kessler Psychological Distress Scale (K10) in the 2012 Aboriginal Peoples Survey. Health Reports, 27(1), 3-10.

Chauhan, N. (2018, August 13). Left alone: Just 2\% of trans people stay with parents. Retrieved June 20, 2020, from https://timesofindia.indiatimes.com/india/lef t-alone-just-2-of-trans-people-stay-withparents/articleshow/65380226.cms

Davis, M., Sabella, K., Smith, L. M., and Costa, A. (2011). Becoming an Adult: Challenges for those with Mental Health Conditions. Psychiatry Information in Brief, 8(15), 1.

Drapeau, A., Marchand, A., and Beaulieu-Prévost, D. (2012). Epidemiology of psychological distress. Mental illnesses-understanding, Prediction and Control, 69, 105-106.

Durso, L. E, \& Gates, G. J. (2012). Serving Our Youth: Findings from a National Survey of Services Providers Working with Lesbian, Gay, Bisexual and Transgender Youth Who Are Homeless or At Risk of Becoming 
Homeless. UCLA: The Williams Institute.

Helliwell, J., Layard, R., Sachs, J., \& De Neve, J. E. (2020). World Happiness Report 2020. New York: Sustainable Development Solutions Network.

Horwitz, A. V. (2007). Distinguishing distress from disorder as psychological outcomes of stressful social arrangements. Health, 11(3), 273-289.

Kessler, R. C., Andrews, G., Colpe, L. J., Hiripi, E., Mroczek, D. K., Normand, S. L., Walters, E. E., and Zaslavsky, A. M. (2002). Short screening scales to monitor population prevalences and trends in non-specific psychological distress. Psychological Medicine, $32 \quad$ (6), 959-976. https://doi.org/10.1017/s0033291702006074

Mental Health America. (n.d.). LGBTQ+ Communities And Mental Health. Retrieved August 17, 2020, from https://www.mhanational.org/issues/lgbtqcommunities-and-mental-health

Mirowsky, J., and Ross, C. E. (2003). Social causes of Psychological Distress, $2^{\text {nd }}$ ed. Hawthorne, N.Y.: Aldine de Gruyter.

National Academies Press (2015) Jan 27. Committee on Improving the Health, Safety, and WellBeing of Young Adults; Board on Children, Youth, and Families; Institute of Medicine; National Research Council.
Washington (DC). ISBN-13: 978-0-30930995-0 ISBN-10: 0-309-30995-6.

Patel, V., Araya, R., Chowdhary, N., King, M., Kirkwood, B., Nayak, S., Simon, G., and Weiss, H. A. (2008). Detecting common mental disorders in primary care in India: a comparison of five screening questionnaires. Psychological medicine, 38(2), $221-228$. https://doi.org/10.1017/S003329170700234

Ridner, S. H. (2004). Psychological distress: concept analysis. Journal of Advanced Nursing, 45(5), 536-545.

Wareham, J. (2020). Map Shows Where It's Illegal to Be Gay - 30 Years Since WHO Declassified Homosexuality As Disease. Retrieved June 16, 2020, from https://www.forbes.com/sites/jamiewareham /2020/05/17/map-shows-where-itsillegal-tobe-gay--30-years-since-who-declassifiedhomosexuality-asdisease/\#27e15ca1578a

\section{Conflict of Interest}

- None of the authors of this paper has a financial or personal relationship with the participants, people or organizations that could inappropriately influence or bias the content of the paper.

- It is to specifically state that "No Competing interests are at stake and there is No Conflict of Interest" with other people or organizations that could inappropriately influence or bias the content of the paper. 


\section{Tables}

\section{Table 1}

Bifurcation of the sample size

\begin{tabular}{lcc}
\hline Sample Bifurcation & India & US \\
\hline LGBTQ+ population & 50 & 50 \\
Cishet population & 50 & 50 \\
Sample size per-country & 100 & 100 \\
Total sample size & & 200
\end{tabular}

\section{Table 2}

Showing difference on Psychological Distress between India and US in (1) Young Adults, (2) LGBTQ+ and (3) Cishet Population

\begin{tabular}{|c|c|c|c|c|c|c|c|}
\hline \multirow[t]{2}{*}{$\mathrm{H}_{1}$ no. } & \multirow[t]{2}{*}{ Population } & \multicolumn{2}{|c|}{ India } & \multicolumn{2}{|c|}{ US } & \multirow[t]{2}{*}{$\mathrm{t}$} & \multirow[t]{2}{*}{$\mathrm{p}$} \\
\hline & & Mean & SD & Mean & SD & & \\
\hline 1.1 & Young Adults & 26.6600 & 7.82797 & 22.2100 & 7.06291 & 4.221 & $0.00003^{*}$ \\
\hline 1.2 & $\begin{array}{l}\text { LGBTQ+ } \\
\text { Population }\end{array}$ & 28.5800 & 8.02061 & 24.2800 & 7.27321 & 2.808 & $.006^{*}$ \\
\hline 1.3 & $\begin{array}{l}\text { Cishet } \\
\text { Population }\end{array}$ & 24.7400 & 7.20773 & 20.1400 & 6.25646 & 3.408 & $.001 *$ \\
\hline
\end{tabular}

Table 3

Showing difference on Psychological Distress between LGBTQ and Cishet population in (1) Young Adults, (2) India and (3) US

\begin{tabular}{clcccccc}
\hline \multirow{2}{*}{ H$_{1}$ no. } & \multirow{2}{*}{ Population } & \multicolumn{2}{c}{ LGBTQ $^{+}$} & \multicolumn{2}{c}{ Cishet } & $\mathrm{t}$ & $\mathrm{p}$ \\
\cline { 3 - 6 } & & Mean & SD & Mean & SD & & \\
\hline 2.1 & Young Adults & 26.4300 & 7.91783 & 22.4400 & 7.10146 & 3.751 & $0.0002^{*}$ \\
\hline 2.2 & India & 28.5800 & 8.02061 & 24.7400 & 7.20773 & 2.518 & $.01^{*}$ \\
\hline 2.3 & US & 24.2800 & 7.27321 & 20.1400 & 6.25646 & 3.051 & $.003^{*}$ \\
\hline
\end{tabular}

$* \mathrm{p}<.01(99 \%$ confidence level $)$ 
Figures

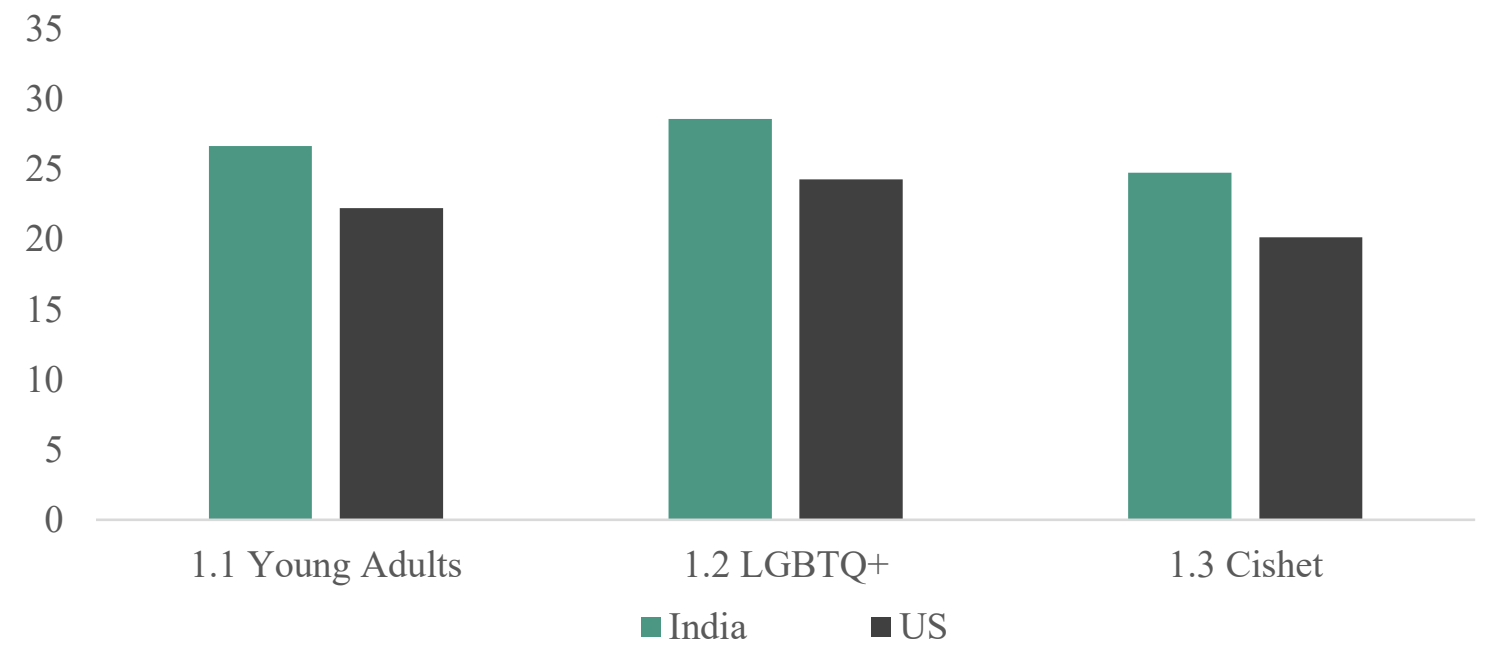

Figure 1: Showing difference in the mean of Psychological Distress among India and US.

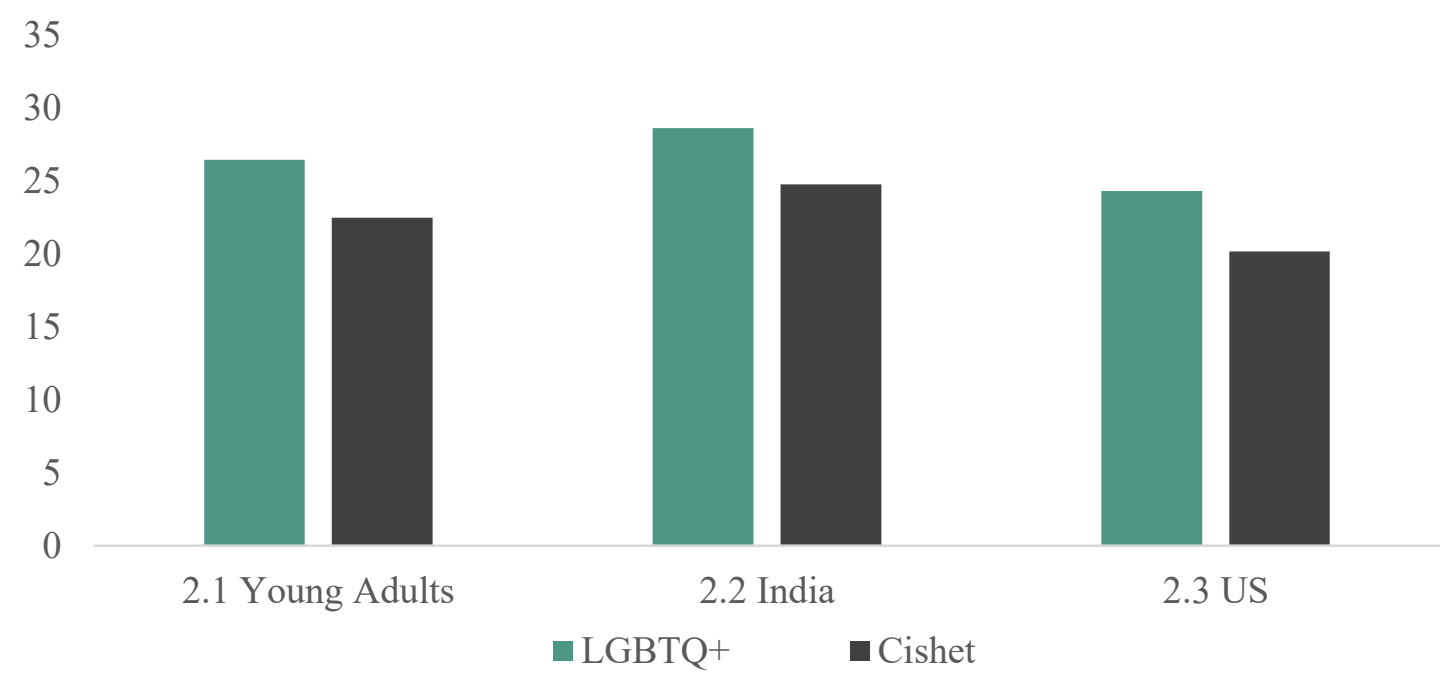

Figure 2: Showing difference in the mean of Psychological Distress among $L G B T Q+$ and Cishet population. 


\section{Acknowledgement}

First and foremost, I would like to acknowledge the LGBTQ+ community that has given me a sense of belongingness, strength and unconditional support fostering me into becoming a person that I once anticipated to become. It's because of the same community that provided me with the ability and knowledge to carry out this research, specially Martha P. Johnson, Sylvia Rivera and many other bold LGBTQ+ liberation activists fighting against discrimination and for the rights and inclusivity that encouraged me to do this research at a professional level. It is because of them that I believe in the power of community and togetherness.
I would like to gratefully acknowledge my supervisor, Dr. Kamini C. Tanwar. Her constructive comments and creative vision has been instrumental in this research. I am especially appreciative of my family for their love and support throughout this process of this research project. Lastly, I would like to express gratitude towards all the participants for sharing the required information that made this research possible and I appreciate their efforts to contribute to this research. I am nothing but thankful to be able to contribute to the field of psychology as well as LGBTQ+ community through this research.

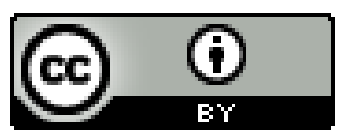

This work is licensed under a Creative Commons Attribution 4.0 International License. 